\title{
Properties of Sodium Caseinate Film-Forming Dispersions and Films
}

\author{
K. Khwaldia, S. Banon, C. Perez, and S. Desobry \\ Laboratoire de Physico-Chimie et Génie Alimentaires, Ecole Nationale Supérieure d'Agronomie et des Industries \\ Alimentaires, Institut National Polytechnique de Lorraine, BP 172, 54505 Vandoeuvre Lès Nancy, Cedex France
}

\section{ABSTRACT}

The flow properties of sodium caseinate (NaCAS) film-forming dispersions were studied as a function of protein and glycerol concentration. Apparent viscosity vs. concentration profiles showed a disruption at about $10 \%$ (wt/wt) NaCAS. This was interpreted in terms of protein-water and protein-protein interactions. The presence of glycerol in the NaCAS film-forming suspensions reduced the viscosity of aqueous $\mathrm{NaCAS}$ as a consequence of decreasing protein-protein and protein-solvent interactions through the hydrogen bonding formation between the glycerol, the polypeptide chain of $\mathrm{NaCAS}$, and water molecules. For higher concentration of glycerol, viscosity of NaCAS dispersions increased as a result of increasing total solid content. The glass transition temperature for solid films of $10 \%$ (wt/wt) NaCAS decreased with the glycerol content. The glycerol-protein interactions reduced the protein-protein interaction and, thus, increased the intermolecular spacing, leading to higher protein chain mobility and water vapor permeability.

(Key words: sodium caseinate, glycerol, viscosity, film)

Abbreviation key: NaCAS = sodium caseinate, PEG = polyethylene glycol, $\mathbf{R H}=$ relative humidity, $\mathbf{W V P}=$ water vapor permeability.

\section{INTRODUCTION}

Considerable interest in edible films, because of their environmentally friendly nature and their potential use in the food industry, has been renewed (Kester and Fennema, 1986; Gennadios and Weller, 1990; Gontard and Guilbert, 1994; Guilbert et al., 1996; Krochta and De-Mulder Johnston, 1997). The properties of edible films have been reviewed more extensively by Guilbert et al. (1995); Krochta (1997); Debeaufort et al. (1998) and Morillon et al. (2000).

These properties, such as barrier, thermal, mechanical, and sensory properties, depend mainly on the na-

Received July 7, 2003.

Accepted February 6, 2004.

Corresponding author: K. Khwaldia; e-mail: khaoula.khwaldia @ensaia.inpl-nancy.fr. ture of components and film and structure. The addition of a plasticizing agent to edible films, such as glycerol, polyethylene glycol (PEG), or sorbitol, is required to overcome film brittleness caused by extensive intermolecular forces (Banker, 1966).

Most edible films are based on starch or vegetal components because of the low price of these components. But, it appeared in the great part of published studies that the high affinity of these edible films to water reduced dramatically their potential use for wet food contact. In the literature, milk proteins were shown to have better barrier properties to mass transfer at high relative humidities (RH) than starch or vegetal proteins (Khwaldia et al., accepted).

In addition to their nutritional value, milk proteins, such as casein, have several key physical characteristics for effective performance in edible films, such as their solubility in water and ability to act as emulsifiers (Southward, 1985). Sodium caseinate (NaCAS) has a desirable flavor and shows excellent water-holding property. It is highly soluble and can be dispersed rapidly in aqueous mixtures and homogenized in the presence of fat or oil (Kinsella, 1984). Sodium caseinate has been shown to be remarkably heat stable at $\mathrm{pH}=6.5$ (Guo et al., 1989). It has poor solubility near its isoelectric point, but the physicochemical and functional properties of the soluble fraction increased dramatically (Lieske and Konrad, 1994). This property was not observed at $\mathrm{pH} 6$ to 8 and $\mathrm{pH} 3$, where the protein has higher solubility. Jahaniaval et al. (2000) reported that this protein undergoes structural changes at $\mathrm{pH} 3.5$ to 4 following heat treatment. Heating $\mathrm{NaCAS}$ at $132^{\circ} \mathrm{C}$ reduced significantly its viscosity and foaming and emulsifying capacity, but its foam stability appeared to be improved by heating (Guo et al., 1996).

Sodium caseinate can easily form films from aqueous solutions because of its random coil nature and its ability to form extensive intermolecular hydrogen electrostatic and hydrophobic bonds, resulting in an increase of the interchain cohesion (Avena Bustillos and Krochta, 1993; McHugh and Krochta, 1994; Brault et al., 1997). Caseinate films exhibit resistance to thermal denaturation and/or coagulation, which means that the protein film remains stable over a wide range of $\mathrm{pH}$, temperature, and salt concentrations (Kinsella, 1984). 
Caseinate films are attractive for use on food products because of their transparent, flexible, and bland nature. They are already used as microencapsulating agents of flavors and medicaments, in coatings of fruits, vegetables, and cheese, as well as in food packaging. Sodium caseinate coating could also be used as a barrier layer at the surface of paper packaging materials.

The aim of this work was to better understand the influence of dispersion composition on protein interactions by investigating the viscous properties of NaCAS film-forming dispersions in terms of protein concentration and glycerol content. The corresponding behavior of the water vapor permeability (WVP) and the glass transition temperature of the NaCAS film were analyzed.

\section{MATERIALS AND METHODS}

\section{Materials}

Commercial NaCAS powder (Lot $21 \mathrm{k} 0118$ ) used to prepare the dispersions was obtained from Sigma Chemical Company (Steinheim, Germany). The protein content, determined by Kjeldahl, was $90.5 \%(\mathrm{~N} \times 6.38)$. The total solid content, determined after heating powder to $102^{\circ} \mathrm{C}$ for $5 \mathrm{~h}$, was $94.6 \%$. The ash content, determined by combustion at $550^{\circ} \mathrm{C}$ for $12 \mathrm{~h}$, was $3.4 \%$. The sodium content of the powder, determined by atomic absorption, was $0.85 \%$.

Glycerol ( $>97 \%$ purity) was used as a plasticizer and was obtained from Merck (Darmstadt, Germany). Sodium azide (Prolabo, Paris, France) was added to protein dispersions to prevent microbial growth.

\section{Preparation of Protein Suspensions and Films}

Sodium caseinate dispersions with concentrations of 8.0, 9.0,10.0, 11.0, 12.0, and $13.0 \%$ (wt/wt) were obtained by dispersing the appropriate NaCAS powder and $0.02 \%(\mathrm{wt} / \mathrm{wt})$ sodium azide in distilled water at $60^{\circ} \mathrm{C}$ while stirring for $30 \mathrm{~min}$. The effect of glycerol content on the viscosity was studied in dispersions with $10 \%$ (wt/wt) NaCAS. The glycerol concentration ranged from 10.0 to $30.0 \%$ when expressed as weight ratio of the plasticizer and NaCAS powder components. The aqueous mixture of NaCAS and glycerol was stirred for $30 \mathrm{~min}$ at room temperature to obtain a homogenous dispersion.

The films for the dynamic mechanical thermal analysis and the WVP measurements were cast from the $10 \%$ (wt/wt) caseinate/glycerol dispersions by pouring the film-forming dispersion $(60 \mathrm{~mL})$ in a polyvinyl chloride plate $(40 \mathrm{~cm} \times 25 \mathrm{~cm})$ and drying overnight at $20^{\circ} \mathrm{C}$ and $50 \% \mathrm{RH}$.

\section{SDS-PAGE}

Sodium dodecyl sulfate-PAGE was performed under denaturing conditions according to the method of Laemmli (1970) in a discontinuous gel system composed of 5 and $12 \%$ acrylamide stacking and running gel, respectively. Sodium caseinate extract was dissolved in sample buffer (0.5 $M$ Tris-HCl [pH 6.8], 10\% SDS, 10\% [vol/ vol] glycerol, $0.5 \%$ [wt/vol] bromophenol blue) in the presence of $5 \%(\mathrm{vol} / \mathrm{vol}) \beta$-mercaptoethanol and heated for $5 \mathrm{~min}$ at $95^{\circ} \mathrm{C}$. The electrode buffer was $25 \mathrm{~m} M$ Tris, $192 \mathrm{~m} M$ glycine, and $0.1 \%$ SDS. Samples ranging from 20 to $60 \mu \mathrm{g}$ were loaded into a vertical Mini-Protean II Electrophoresis Cell (Bio-Rad Laboratories Inc., Hercules, CA) at $30 \mathrm{~mA}$ for $1 \mathrm{~h}$. The gel was stained with a Coomassie brilliant blue R-250 (Sigma Chemical Co., St. Louis, MO) in 7.5\% (vol/vol) acetic acid $/ 40 \%$ (vol/ vol) methanol and destained with $7.5 \%$ (vol/vol) acetic acid $/ 15 \%$ ( $\mathrm{vol} / \mathrm{vol}$ ) methanol. The gel was dried between cellophane sheets.

\section{Viscosity Experiments}

Shear stress at different shear rates was measured using a rotational rheometer (Reologica AB; Stress Tech, Lunds, Sweden) at $23^{\circ} \mathrm{C}$. The measurement geometry was a 4-cm cone (C40 4) and plate with a cone angle of $2^{\circ}$ and a gap of $52 \mu \mathrm{m}$. Each experiment was replicated 4 times $(n=4)$.

\section{Thermomechanical Properties}

Dynamic mechanical thermal analysis of films was conducted with a Perkin Elmer apparatus DMA-7 (Norwalk, CT) equipped with a cryogenic system fed with liquid nitrogen (Air Liquide, Aix-en-Provence, France). A variable-amplitude, sinusoidal mechanical stress was applied to the sample (frequency $=1 \mathrm{~Hz}$ ) to produce a sinusoidal strain of selected amplitude. The compression mode of deformation was chosen for use with the sample geometry. Temperature scans from -30 to $260^{\circ} \mathrm{C}$ were performed at a heating rate of $3^{\circ} \mathrm{C} / \mathrm{min}$. The furnace temperature was calibrated with indium (Perkin Elmer Standard) and was flushed with dry nitrogen gas during analysis to avoid hydration of the films. The samples were dehydrated before testing to avoid the plasticizing effect of the water content. For each material, 3 samples were tested $(\mathrm{n}=3)$. During analysis, the stored values were the storage modulus (E') and the loss tangent $(\tan \delta)$. The glass transition temperature $\left(\mathrm{T}_{\mathrm{g}}\right)$ was determined from the maximum of the tan $\delta$ peak $(\mathrm{T}(\tan \delta))$. 


\section{WVP}

Water vapor permeability of the films was determined with the gravimetric method described in the AFNOR NF H00-030 standard (1974). The test film was sealed in a glass permeation cell containing a desiccant (silica gel). The glass permeation cells were $5.8 \mathrm{~cm}$ (i.d.) $\times 7.8 \mathrm{~cm}$ (o.d.) $\times 3.6 \mathrm{~cm}$ deep with an exposed area of $26.42 \mathrm{~cm}^{2}$. The permeation cells were placed in a controlled temperature $\left(20 \pm 3^{\circ} \mathrm{C}\right)$ and $\mathrm{RH}(90 \pm 3 \%)$ chamber via ventilation. The water vapor transport was determined from the weight gain of the cell. After 30 min, steady-state conditions were reached, and weightings were made. Six replicates were made from each film composition $(n=6)$.

Water vapor transmission rate (WVTR), permeance (P), and WVP of the film were calculated as follows (McHugh and Krochta, 1994):

$$
\begin{gathered}
\text { WVTR }=\mathrm{dM} / \mathrm{dt} \mathrm{A}\left(\mathrm{g} \cdot \mathrm{d}^{-1} \cdot \mathrm{m}^{-2}\right) \\
\mathrm{P}=\mathrm{WVTR} / \Delta \mathrm{p}\left(\mathrm{g} \cdot \mathrm{d}^{-1} \cdot \mathrm{m}^{-2} \cdot \mathrm{KPa}^{-1}\right) \\
\mathrm{WVP}=\mathrm{P} \times \mathrm{X}\left(\mathrm{g} \cdot \mu \mathrm{m} \cdot \mathrm{m}^{-2} \cdot \mathrm{d}^{-1} \cdot \mathrm{KPa}^{-1}\right)
\end{gathered}
$$

where $d M$ is the weight gain of the cup over time (dt), A is the area of exposed film, $\Delta \mathrm{p}$ is the vapor pressure differential across the film, and $\mathrm{X}$ is the film thickness.

\section{RESULTS AND DISCUSSION}

\section{SDS-PAGE Electrophoresis}

The PAGE traces for NaCAS solutions are shown in Figure 1. When separated by 1-D PAGE, the patterns of NaCAS solutions showed 3 major fractions of casein, which are in agreement with the main fractions $\alpha_{\mathrm{s} 1}, \beta$, and $\kappa$-casein present in the milk casein. These fractions correspond to a molecular weight of approximately 30 , 27 , and $24 \mathrm{kDa}$, respectively.

\section{Viscosity of NaCAS Dispersions}

Figure 2 shows the flow curves of NaCAS dispersions at various concentrations. The dispersions of caseinate can be divided into 2 categories with respect to flow properties. At concentrations $<9 \%$, the dispersions were essentially Newtonian, exhibiting little or no change in viscosity as a function of shear rate. At concentrations $>9 \%$, they were slightly shear thickening.

As seen from Figure 3, the viscosity of caseinate was very concentration dependent. The apparent viscosity

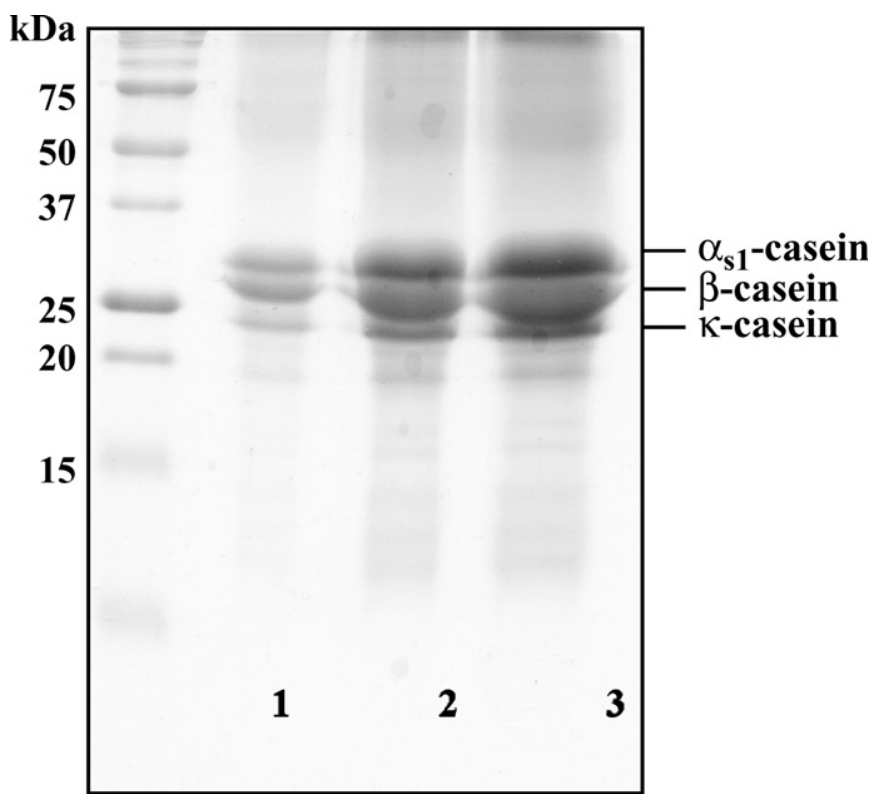

Figure 1. Sodium dodecyl sulfate-PAGE of sodium caseinate (NaCAS) solutions. Columns 1 to 3 represent a gradient of concentrations (20 to $60 \mu \mathrm{g})$.

of caseinate increased with increasing protein concentration. The relationship of concentration with the logarithm of the viscosity of the NaCAS was essentially linear when the concentration was $\geq 10 \%$. This is in accordance with results from Hayes et al. (1969), Yadav and Roy (1969), and Hermansson (1975). Those authors reported that the logarithm of viscosity is directly proportional to NaCAS concentration over a broad concentration range (12 to $20 \%$ [wt/wt]).

It can be noted that, at a similar concentration, caseinate shows a much higher apparent viscosity than whey protein concentrate (Hermansson, 1975).

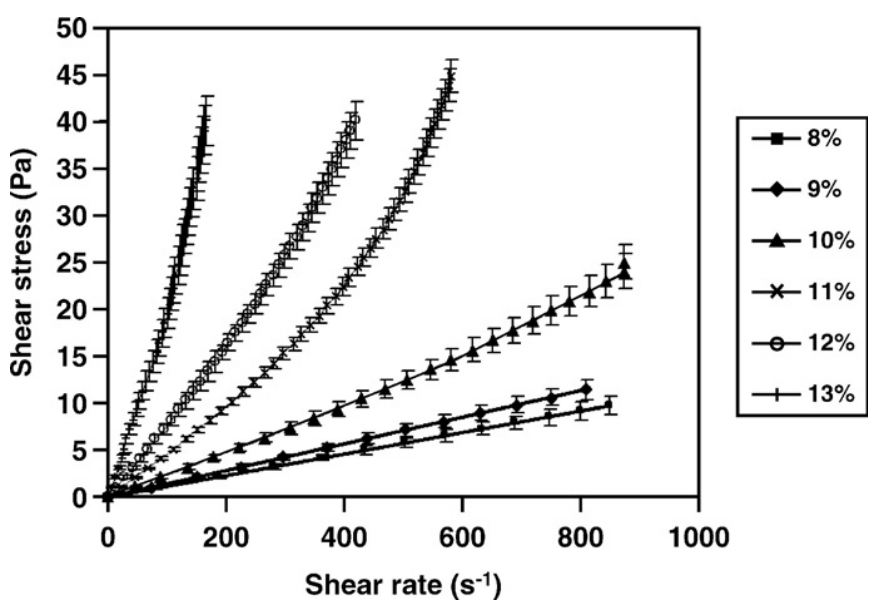

Figure 2. Flow curves at various concentrations of sodium caseinate dispersions (wt/wt) $\left(23^{\circ} \mathrm{C}\right)(\mathrm{n}=4)$. 


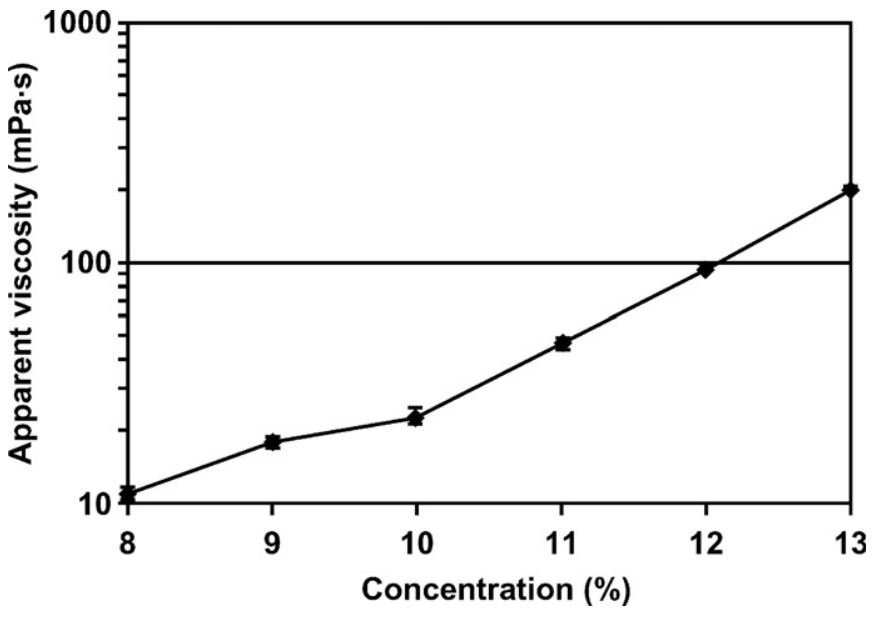

Figure 3. Viscosity as a function of sodium caseinate concentration $(\mathrm{wt} / \mathrm{wt})$ at $120 \mathrm{~s}^{-1}\left(23^{\circ} \mathrm{C}\right)(\mathrm{n}=4)$.

\section{Effect of Glycerol on the Viscosity of NaCAS Dispersions}

Figure 4 shows that glycerol decreases the viscosity of the caseinate dispersion. Glycerol, as a plasticizer, interacts with the NaCAS chain and water molecules through hydrogen bonding, leading to the disruption of the protein-protein and protein-solvent interactions. The viscosity decrease in dispersions of $\mathrm{NaCAS}$ in the presence of another plasticizer (sorbitol) has been reported by Barreto et al. (accepted). Those authors attribute the decrease in viscosity to the protein dehydration. Indeed, the presence of sorbitol in the solution must have disrupted the hydrogen bonding between NaCAS and water and, consequently, the partial specific volume.

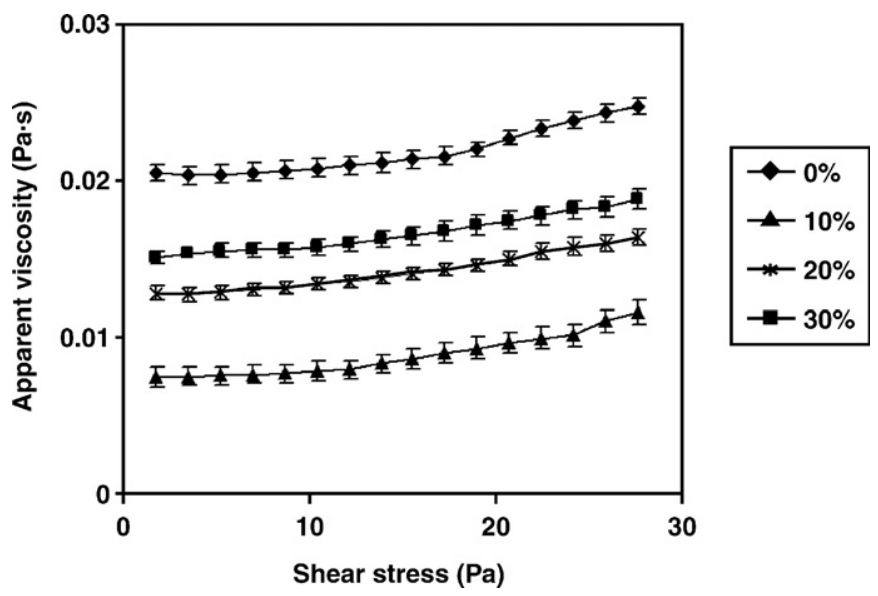

Figure 4. Effect of glycerol concentration (g/100 g of sodium caseinate $[\mathrm{NaCAS}]$ powder) on the viscosity of $10 \%(\mathrm{wt} / \mathrm{wt})$ sodium caseinate at $23^{\circ} \mathrm{C}(\mathrm{n}=4)$.

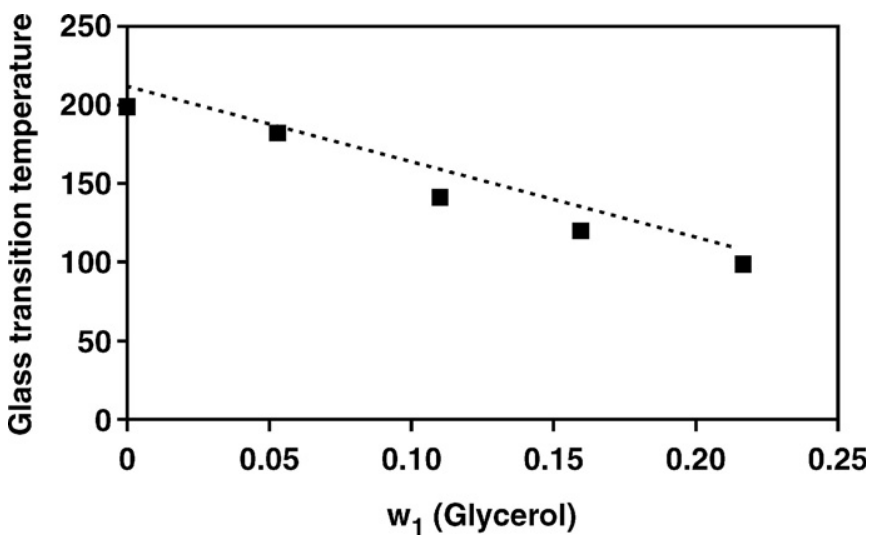

Figure 5. Glass transition temperature of sodium caseinate-glycerol films as a function of the $M$ glycerol content: $\mathbf{\square}=$ experimental values and fitting, considering the (- - ) Couchman-Karasz equation $(\mathrm{n}=3) . \mathrm{w}_{1}=$ molar fraction of glycerol.

The viscosity of the solution increases with glycerol content (Figure 4), which can be attributed to the decrease in the free solvent volume as glycerol molecules interact with the NaCAS chain. Similar behavior has also been observed by Soloshenko et al. (1984) and Siew et al. (1999). Siew et al. (1999) attribute the viscosity increase with glycerol content to the formation of larger NaCAS-glycerol aggregates as glycerol molecules interact with the NaCAS chain.

\section{Glass Transition Temperatures of Films}

The glass transition temperature was determined by dynamic mechanical thermal analysis. The 10\% (wt/ wt) NaCAS dispersion was selected to obtain a suitable dispersion viscosity and concentration for casting. At this concentration, the NaCAS hydration is supposed to be completely achieved.

At the glass transition, there is a large increase of molecular mobility, so that the glass transition temperature is extremely "structure-sensitive," partly because of steric effects and partly because of intra- and intermolecular interactions. Generally, glass transition temperature increases with the size, rigidity, and polarity of side groups of the macromolecules. An effective plasticizer has to break the attachments that hold the polymer chains together, facilitating the segmental mobility.

The presence of glycerol had a significant plasticizing effect on the NaCAS film (Figure 5), and the observation of a single glass transition (in the range of studied temperature) reflects compatibility between glycerol and NaCAS. The glass transition temperature of $\mathrm{Na}-$ $\mathrm{CAS}$ and NaCAS-glycerol films as a function of $M$ plasti- 
Table 1. Effect of glycerol content on water vapor permeability (WVP) of sodium caseinate $(\mathrm{NaCAS})$ films (temperature $=20^{\circ} \mathrm{C}$; (relative humidity $=90 \%$; thickness $=100 \mu \mathrm{m})(\mathrm{n}=6)$.

\begin{tabular}{lc}
\hline Film & WVP \\
\hline (glycerol:NaCAS ratio) & $\left(\mathrm{g} \cdot \mu \mathrm{m} \cdot \mathrm{m}^{-2} \cdot \mathrm{d}^{-1} \cdot \mathrm{KPa}^{-1}\right)$ \\
$(0: 100)^{1}$ & $7.3 \pm 0.5$ \\
$(10: 100)$ & $24 \pm 1.2$ \\
$(20: 100)$ & $102 \pm 3.5$ \\
$(30: 100)$ & $200 \pm 5.3$ \\
\hline
\end{tabular}

${ }^{1}$ Ratios in parentheses refer to the weight ratio of glycerol to NaCAS powder.

cizer content was analyzed using the Couchman-Karasz equation.

$$
\mathrm{Tg}=\frac{\mathrm{w}_{1} \mathrm{Tg}_{1} \Delta \mathrm{Cp}_{1}+\mathrm{w}_{2} \mathrm{Tg}_{2} \Delta \mathrm{Cp}_{2}}{\mathrm{w}_{1} \Delta \mathrm{Cp}_{1}+\mathrm{w}_{2} \Delta \mathrm{Cp}_{2}}
$$

Where $\mathrm{w}_{1}$ and $\mathrm{w}_{2}$ are the $M$ fractions, and $\Delta \mathrm{Cp}_{1}(0.88$ $\left.\mathrm{J} \cdot \mathrm{g}^{-1} \cdot \mathrm{K}^{-1}\right)$ and $\Delta \mathrm{Cp}_{2}\left(0.5 \mathrm{~J} \cdot \mathrm{g}^{-1} \cdot \mathrm{K}^{-1}\right)$ are the specific heat capacities of glycerol and NaCAS, respectively. There is good agreement between experimental and theoretical values of glass transition temperature, suggesting effective interaction between NaCAS and glycerol. The plasticizing effect of glycerol could be attributed to its low molecular weight and the presence of hydroxyl groups. Indeed, glycerol can be easily inserted between the side chains, and, therefore, glycerol has a high probability of hydrogen bonding at all hydrophilic locations, that is, low hydrophobicity sites. Interactions of the protein chains in the NaCAS-glycerol films are thus reduced, and intermolecular spacing is increased, facilitating movement of the protein chains and leading to lower values of glass transition temperatures as shown in Figure 5.

Siew et al. (1999) studied the plasticizing effect of glycerol and PEG on NaCAS films. They observed that the transition in the glycerol films occurs over a broader plasticizer range, suggesting that the PEG system is more structured in terms of a more homogeneous bonding distribution.

\section{WVP of NaCAS Films}

Table 1 shows that the film WVP increased with increasing glycerol content in the film. An increase in the interchain spacing caused by inclusion of glycerol molecules between the polymer chains may promote water vapor diffusivity through the film and, hence, accelerate the water vapor transmission. The high hydrophilicity of glycerol molecules, which is favorable to the adsorption of water molecules, could also contribute to the increase in the film WVP.
Using whey protein films, McHugh et al. (1994) also reported increasing water vapor transmission with increasing glycerol.

Glass transition theory can be utilized to explain glycerol effects on WVP properties. Glass transition temperatures of NaCAS films are lowered by glycerol (Figure 5). Glycerol increases the free volume of the protein network, thereby increasing polymer mobility and WVP.

\section{CONCLUSIONS}

This study has shown that both protein concentration and glycerol content influenced the viscous properties of NaCAS film-forming dispersions by altering the magnitude and range of protein-water and protein-protein interactions in aqueous systems. The decrease in the glass transition temperature observed for the solid films of NACAS with glycerol addition depends on the properties of the film-forming dispersions.

The thrust for future work is to develop NaCAS coating on paper/paperboard or plastic. The NaCAS-coated paper will be fully compostible. An NaCAS coating on plastic has the advantage of being easily removed for recycling of the plastic. Sodium caseinate coating can provide not only better physical performance of packaging materials and prolonged shelf-life of foods, but also reduce solid waste and improve plastic recycling.

\section{REFERENCES}

AFNOR. 1974. Détermination du Coefficient de Transmission à la Vapeur d'eau pour Matières en Feuilles. NF H 00-030. Association Française de Normalisation, Paris.

Avena Bustillos, R. J., and J. M. Krochta. 1993. Water vapor permeability of caseinate-based films as affected by $\mathrm{pH}$, calcium crosslinking, and lipid content. J. Food Sci. 58:904-907.

Banker, G. S. 1966. Film coating, theory and practice. J. Pharmacol. Sci. 55:81-89.

Barreto, P. L. M., J. Roeder, J. S. Crespo, G. R. Maciel, H. Terenzi, A. T. N. Pires, and V. Soldi. Effect of concentration, temperature and plasticizer content on rheological properties of sodium caseinate and sodium caseinate/sorbitol solutions and glass transition of their films. Food Chem. (accepted)

Brault, D., G. D'Aprano, and M. Lacroix. 1997. Formation of freestanding sterilized edible films from irradiated caseinates. J. Agric. Food Chem. 45:2964-2969.

Debeaufort, F., J. A. Quezada-Gallo, and A. Voilley. 1998. Edible films and coatings: Tomorrow's packaging: A review. Crit. Rev. Food Sci. 38:299-313.

Gennadios, A., and C. L. Weller. 1990. Edible films and coatings from wheat and corn proteins. Food Technol. 44:63-69.

Gontard, N., and S. Guilbert. 1994. Bio-packaging: technology and properties of edible and/or biodegradable materials of agricultural origin. Pages 159-181 in Food Packaging and Preservation. M. Mathlouthi, ed. Blackie Academic \& Professional, London, United Kingdom.

Guilbert, S., N. Gontard, and B. Cuq. 1995. Technology and applications of edible protective films. Packag. Technol. Sci. 8:339-346.

Guilbert, S., N. Gontard, and L. G. M. Gorris. 1996. Prolongation of the shelf life of perishable food products using biodegradable films and coatings. Lebensm.Wiss. Technol. 29:10-17. 
Guo, M., P. F. Fox, A. Flynn, and K. S. Mohammad. 1989. Heatinduced changes in sodium caseinate. J. Dairy Res. 56:503-512.

Guo, M., P. F. Fox, A. Flynn, and P. S. Kindstedt. 1996. Heat-induced modification of the functional properties of sodium caseinate. Int. Dairy J. 6:473-485.

Hayes, J. F., L. L. Muller, and P. Fraser. 1969. Studies on co-precipitates of milk proteins. Part 5. Investigations on viscosity of coprecipitates in dispersions of high concentrations. Aust. J. Dairy Technol. 24:75.

Hermansson, A. M. 1975. Functional properties of proteins for foods: Flow properties. J. Texture Stud. 5:425-439.

Jahaniaval, F., Y. Kakuda, V. Abraham, and M. F. Marcone. 2000. Soluble protein fractions from $\mathrm{pH}$ and heat treated sodium caseinate: Physicochemical and functional properties. Food Res. Int. 33:637-647.

Kester, J. J., and O. R. Fennema. 1986. Edible films and coatings: A review. Food Technol. 40:47-59.

Khwaldia, K., C. Perez, S. Banon, S. Desobry, and J. Hardy. Milk proteins for edible films and coatings. Crit. Rev. Food Sci. Nutr. (accepted).

Kinsella, J. E. 1984. Milk proteins: Physicochemical and functional properties. Crit. Rev. Food Sci. Nutr. 21:197-262.

Krochta, J. M. 1997. Edible protein films and coatings. Pages 529549 in Food Proteins and Their Applications. S. Damodaran and A. Paraf, ed. Marcel Dekker, Inc., New York, NY.

Krochta, J. M., and C. D. De-Mulder-Johnston. 1997. Edible and biodegradable polymer films: Challenges and opportunities. Food Technol. 51:61-74.
Laemmli, U. K. 1970. Cleavage of structural proteins during the assembly of the head of bacteriophage T4. Nature 227:680-685.

Lieske, B., and G. Konrad. 1994. Thermal modification of sodium caseiante. 1 . Influence of temperature and $\mathrm{pH}$ on selected physicochemical and functional properties. Milchwissenschaft. 49:16-20.

McHugh, T. H., and J. M. Krochta. 1994. Permeability properties of edible films. Pages 139-187 in Edible Coating and Films to Improve Food Quality. J. M. Krochta, E. A. Baldwin, and M. Nisperos Carriedo, ed. Technomic Publishing Co., Inc., Lancaster, PA.

McHugh, T. H., J. F. Aujard, and J. M. Krochta. 1994. Plasticized whey protein edible films: Water vapor permeability properties. J. Food Sci. 59:416-419, 423.

Morillon, V., F. Debeaufort, M. Capelle, G. Blond, and A. Voilley. 2000. Influence of the physical state of water on the barrier properties of hydrophilic and hydrophobic films. J. Agric. Food Chem. 48:11-16.

Siew, D. C. W., C. Heilmann, A. J. Easteal, and R. P. Cooney. 1999 Solution and film properties of sodium caseinate/glycerol and sodium caseinate/polyethylene glycol edible coating systems. J. Agri. Food Chem. 47:3432-3440.

Southward, C. R. 1985. Manufacture and applications of edible casein products. I. Manufacture and properties. N. Z. J. Dairy Sci. Technol. 20:79.

Soloshenko, V. M., V. A. Sergeev, and M. G. Bezrukov. 1984. Structure of protein solutions. Part 1. Investigation and interpretation of viscosity anomalies. Nahrung 28:459-472.

Yadav, P. L., and N. K. Roy. 1969. Viscometric study of interactions between the major milk constituents in model milk systems. Indian J. Dairy Sci. 22:21. 